\title{
Plant pattern-recognition receptors controlling innate immunity
}

\author{
Lei Li, Yufei Yu, Zhaoyang Zhou* \& Jian-Min Zhou** \\ State Key Laboratory of Plant Genomics, Institute of Genetics and Developmental Biology, Chinese Academy of Sciences, Beijing 100101, China
}

Received May 20,2016; accepted June 2, 2016; published online August 16, 2016

Citation: Li, L., Yu, Y., Zhou, Z. and Zhou, J.M. (2016). Plant pattern-recognition receptors controlling innate immunity. Sci China Life Sci 59, 878-888. doi: $10.1007 / \mathrm{s} 11427-016-0115-2$

\section{INTRODUCTION}

Unlike animals, plants lack an adaptive immune system, and entirely rely on innate immunity to resist numerous potential pathogens in their environment (Jones and Dangl, 2006; Boller and Felix, 2009). They have evolved diverse immune receptors to detect potential pathogenic microbes via recognition of pathogen-associated molecular patterns (PAMPs) and effectors encoded by pathogens. PAMPs can be detected by surface-localized pattern-recognition receptors (PRRs) that are receptor kinases (RKs) or receptor proteins (RPs), thereby activating pattern-triggered immunity (PTI). Plant PRRs are structurally and functionally analogous to animal Toll-like receptors (TLRs). In addition to microbial molecules, some PRRs can recognize damage-associated molecular patterns (DAMPs) that are plant derived molecules released during pathogen infection. Phytopathogens are capable of secreting effectors into plant apoplast or cytoplasm to enhance virulence. However, further evolution in plants has resulted in PRRs that recognize apoplastic effectors and intracellular immune receptors that recognize cytoplasmic effectors. Plant intracellular immune receptors contain nucleotide-binding, leucine-rich repeat domains and are homologous to animal NOD-like receptors (NLRs). Immunity initiated by NLRs is also referred to as effector-triggered immunity.

Plant receptor-like kinases (RLKs) and receptor-like proteins (RLPs) play diverse role in plant growth, development,

\footnotetext{
*Corresponding author (email: zhaoyangzhou@genetics.ac.cn)
}

**Corresponding author (email: jmzhou@genetics.ac.cn) reproduction, adaptation to abiotic stress, symbiosis, and disease resistance (Morris and Walker, 2003; Tör et al., 2009). To date, only a relatively small number of RLKs and RLPs, such as XA21, FLS2, and EFR, have been shown to directly perceive ligands. They are referred to as RKs and RPs in this review. Plant genomes encode a large number of RLKs and RLPs, many of which show lineage-specific expansion, suggesting a role in the adaptation to pathogens (Shiu and Bleecker, 2001; Shin-Han and Bleecker, 2003). Indeed, a growing number of RLKs and RLPs have been found to be PRRs. Recent advances have uncovered commonalities and differences concerning how PRRs recognize diverse ligands to activate downstream signaling. In this review, we discuss our current understanding of biological functions, mechanisms of PRR activation, and dynamic regulation of receptor complexes during immune signaling.

\section{RLKS AND RLPS BELONG TO SUPER FAMI- LIES IN HIGHER PLANTS}

RLKs and RLPs mediate perception of a variety of endogenous or exogenous signals (Tör et al., 2009). An RLK contains a single-pass transmembrane domain, an intracellular kinase domain, and an extracellular domain (ECD), which perceives extracellular molecules (Gómez-Gómez and Boller, 2000; Li and Chory, 1997; Zipfel et al., 2006). In contrast, RLPs only have a very short intracellular domain and lack kinase domain (Gust and Felix, 2014; Liebrand et al., 2014). The number of RLKs and RLPs in plants far exceeds their counterparts in 
animals (Shiu and Bleecker, 2001). There are $\sim 410$ RLKs and 170 RLPs in Arabidopsis, 640 RLKs and 90 RLPs in rice (Fritz-Laylin et al., 2005; Shiu and Bleecker, 2001; Shiu et al., 2004) (Figure 1A and B), among which many members are functionally unknown. The expansion of RLK and RLP families in plants is likely linked to the sessile nature of plants, which cannot escape from assaults from their surrounding environment. And the presence of a large number of RLKs and RLPs might have played a fundamental role in the success of terrestrial plants.

RLKs and RLPs are divided into multiple subfamilies according to their ECDs which include leucine-rich repeat (LRR), lysin motif (LysM), Lectin, and epidermal growth factor-like (EGF) domains (Macho and Zipfel, 2014). The LRR subfamilies are the largest among RLKs and RLPs (Figure 1B). Phylogenetic analyses showed that the LRR-XII subfamily of Arabidopsis RLK, which contains multiple PRRs, undergoes an expansion possibly as a result of host-pathogen co-evolution (Shiu et al., 2004; $\mathrm{Wu}$ and Zhou, 2013). Although the number of RLPs is much smaller than RLKs, they also possess diverse ECDs, and their expansion is similarly linked to host adaptation to pathogens. Indeed, recent advances have identified several RLPs as new PRRs (Albert et al., 2015; Jehle et al., 2013; Zhang et al., 2013, 2014).

\section{RKS AND RPS AS PRRS}

Up to now, only a handful PRR-ligand pairs have been elucidated. And different subfamilies of PRRs exhibit the commonalities and differences in recognition of diverse ligands.

LRR-containing RLKs are the largest subfamilies in Ara-
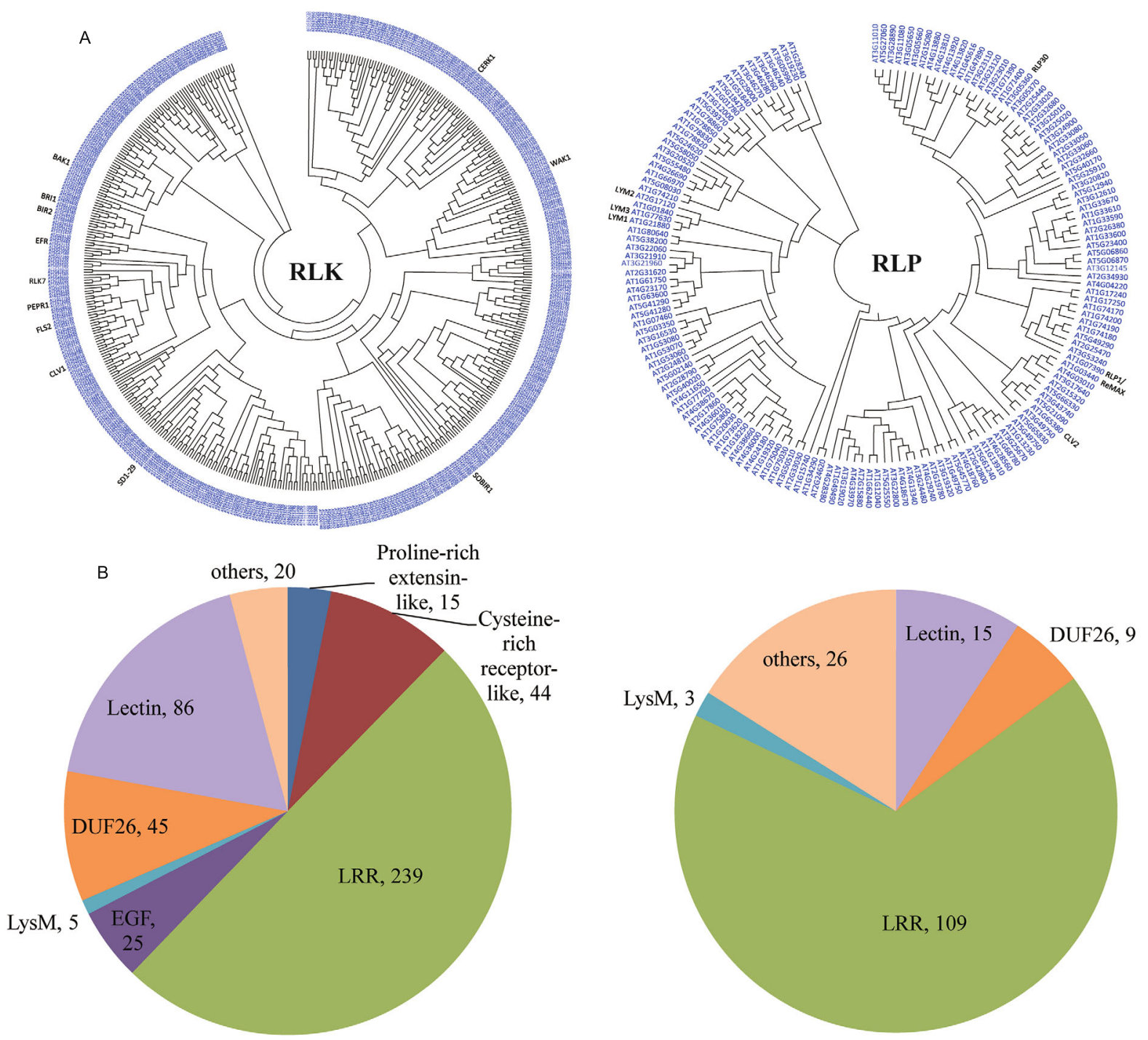

Figure 1 An expanded RLK/RLP gene families in plant kingdom. A, Phylogenetic tree of RLK/RLP in Arabidopsis. All known Arabidopsis RLK and RLP sequences were retrieved from the genome database, and full length sequences were aligned to generate the neighbor-joining tree by ClustalX 2.0 . B, The number of genes with indicated extracellular domain in Arabidopsis. 
bidopsis genome with more than 230 members. Several well-known PRRs are RKs belonging to these subfamilies. The Arabidopsis RK FLS2 is the receptor of a conserved 22 amino acid epitope (flg22) of bacterial flagellin, defining the first plant PRR-PAMP pair to be identified (Bauer et al., 2001; Gómez-Gómez and Boller, 2000). Surprisingly, the mammalian immune receptor TLR5 also recognizes bacterial flagellin through binding to a different epitope (Hayashi et al., 2001; Yoon et al., 2012). Although both TLR5 and FLS2 contain LRR ectodomains, they have evolved independently and recognize different parts of flagellin (Boller and Felix, 2009; Nürnberger et al., 2004). Another well-studied PRR is the Arabidopsis LRR-RK EFR that senses the $\mathrm{N}$-acetylated peptide with 18 amino acids of the N-terminus of elongation factor Tu (EF-Tu), which is the most abundant protein in the bacterial cell (Kunze et al., 2004; Zipfel et al., 2006). In addition, the rice LRR-RK XA21 perceives the tyrosine-sulfated protein RaxX from Xanthomonas oryzae pv. oryzae (Xoo) species to trigger effective resistance to Xoo (Pruitt et al., 2015; Wei et al., 2016). The Arabidopsis LRR-RKs PEPR1 and PEPR2 perceive conserved Pep sequence shared by a small family of Arabidopsis ProPep proteins that are released during pathogen infection (Huffaker and Ryan, 2007; Krol et al., 2010; Yamaguchi et al., 2010). Pep perception not only amplifies the PTI signaling (Liu et al., 2013b; Tintor et al., 2013), but also contributes to systemic acquired resistance (Ross et al., 2014). Recent findings indicate that Pep perception also allows plants to sense the perturbation of immune system by pathogens (Yamada et al., 2016). Similar to Pep, another plant endogenous peptide PIP1 was induced by a variety of pathogens and PAMPs. The LRR-RK RLK7 can bind PIP1 and is required for PIP1-induced immune signaling, suggesting that RLK7 is a potential PRR for PIP1 (Hou et al., 2014). RLK7 may cooperate with PEPR to amplify the immune response triggered by PAMPs. Interestingly, FLS2, EFR, PEPR, RLK7, and XA21 all belong to subfamily LRR-XII of RLKs (Shiu et al., 2004), but they bind different ligands, suggesting that this subfamily RLKs might recognize diverse proteinaceous ligands for immune activation.

Similar to LRR-RLKs, a large number of LRR-RLPs $(\sim 100)$ were found existing in Arabidopsis genome. Several LRR-RLPs have been identified as likely PRRs. The Arabidopsis RLP1/ReMAX detects a Xanthomonas protein, although molecular identity of which is unknown (Jehle et al., 2013). RLP30 recognizes an unknown proteinaceous elicitor from the necrotrophic fungal pathogen Sclerotinia sclerotiorum (Zhang et al., 2013). The Arabidopsis RLP42, is required for the recognition of fungal endopolygalacturonases (Zhang et al., 2014). The Arabidopsis RLP23 recognizes necrosis and ethylene-inducing peptide 1-like proteins, a large class of proteins secreted by bacterial, fungal and oomycete pathogens, to activate immunity in a manner dependent on RLKs SOBIR1 and BAK1 (Albert et al., 2015). Besides PAMPs, many filamentous phytopathogens apoplastic effectors are also perceived by RLPs (de Jonge et al. 2011). The tomato Cf proteins are LRR-RLPs that confer resistance to $C$. fulvum carrying cognate apoplastic effectors (Joosten and de Wit, 1999). For instance, the tomato RLP Cf-2 recognizes the C. fulvum apoplastic effector Avr2 to induce hypersensitive response, although the ligand responsible for this recognition has yet to be identified (Dixon et al., 1996; Kruger et al., 2002; Luderer et al., 2002; Rooney et al., 2005). In addition, the tomato RLPs Cf-4, Cf-9 and Cf-4E can perceive C. fulvum effectors Avr4, Avr9, and Avr4E, respectively (Wulff et al., 2009). These findings suggest that RKs and RPs with LRR ECDs specialized in the recognition of proteinaceous ligands.

While Arabidopsis encodes only five LysM-containing RLKs and three RLPs, more evidence showed that they play important roles in triggering plant defenses by sensing specific fungal chitin and bacterial peptidoglycan (PGN), which are microbial $\mathrm{N}$-acetylglucosamine (GlcNAc)-containing glycans and can act as PAMPs (Silipo et al., 2010). In rice, the LysM-RP CEBiP is the high affinity chitin receptor (Kaku et al., 2006). Chitin-triggered immunity also requires CERK1, a LysM-RLK (Shimizu et al., 2010). Arabidopsis does not appear to carry a functional counterpart of CEBiP. Instead, the Arabidopsis LysM-RK CERK1 has been shown to bind chitin and is required for chitin-induced immunity (Liu et al., 2012b; Miya et al., 2007; Petutschnig et al., 2010; Wan et al., 2008). A recent report suggests that another Arabidopsis LysM-RK, LYK5, is a high affinity chitin receptor (Cao et al., 2014). Likewise, PGN can elicit defense responses in plants (Gust et al., 2007; Erbs et al., 2008). In Arabidopsis, the LysM-RPs LYM1 and LYM3 specifically bind PGN to trigger resistance to bacterial pathogens (Willmann et al., 2011; Shinya et al., 2012). CERK1, although does not bind PGNs, is also required for PGN-induced immunity (Shinya et al., 2012; Willmann et al., 2011). Moreover, the rice LysM-RLPs LYP4 and LYP6 act together with CERK1 for PGN-induced immunity (Liu et al., 2012a; Gust, 2015). The LysM-mediated perception of PGN in plants contrast PGN perception in mammals, which involve structurally diverse immune receptors including the founding members of NLR proteins NOD1 and NOD2, TLR2, and PGN recognition proteins (PGRPs, PGLYRPs) (Chamaillard et al., 2003; Dziarski and Gupta, 2010; Girardin et al., 2003; Kurata, 2010; Takeuchi et al., 1999). In adition, RLKs or RLPs carrying LysM domain are also involved in recognition of Nod factors (NFs) and Myc factors (MFs), which are rhizobium/arbuscular mycorrhiza-derived chitin-related lipochitooligosaccharides with short carbon backbones (3-5 N-GlcNAc residues) (Gust et al., 2012). For example, Lotus japonicus LysM-RKs NF receptor 1 (NFR1) 
and NFR5, Medicago truncatula NF perception (NFP) and LYK3, and Pisum sativum Sym 37 and Sym10 are required for recognizing NFs of Rhizobium (Amor et al., 2003; Limpens et al., 2003; Madsen et al., 2003; Radutoiu et al., 2003; Smit et al., 2007; Zhukov et al., 2008). Moreover, Parasponia andersonii NFP and Medicago truncatula NFP are also required for the perception of MFs during symbiosis with arbuscular mycorhiza (Op den Camp et al., 2011; Maillet et al., 2011). These findings demonstrate that plant LysM receptors are specialized in the recognition of GlcNAc-containing microbial signals to mediate plant immune activation or symbiosis.

Arabidopsis encodes approximately 100 proteins with Lectin ECDs, several of which have also been shown to play an important role in plant immunity. LORE, an RK containing a plant specific B-type Lectin domain, senses lipopolysaccharide (LPS), a major component of the outer membrane of Gram-negative bacteria (Vaid et al., 2012; Ranf et al., 2015). LPS are composed of O-antigen biological repeats, core oligosaccharide, and lipid A (Knirel et al., 2006). LORE binds LPS mainly through lipid A, which is similar to the recognition of LPS lipid A moiety by mammalian immune receptor TLR4 that activates proinflammatory responses (Park et al., 2009; Tan and Kagan, 2014). However, TLR4 carries an LRR ECD instead of a Lectin ECD. It is unexpected that the lipid A moiety is recognized by receptors of completely different structure in plants and mammals. One possibility is that these receptors detect distinct acylation patterns existing in plant and animal bacterial pathogens (Ranf et al., 2015). Another Lectin family PRR LecRK-I.9 has been shown to perceive extracellular ATP (eATP) to regulate cellular responses (Choi et al., 2014). As ATP is probably released by plant cell into extracellular matrix during wounding and infection of pathogen, ATP can be considered as another DAMP. In addition, the Lectin-RLK LecRK-VI.2 was found to act as a key modulator in plant PTI responses, although the underlying mechanism remains unknown (Singh et al., 2012). Recently, three G-type Lectin family RLKs LecRK1, LecRK2 and LecRK3 were shown to be required for brown planthopper resistance in rice (Liu et al., 2015). Broad-spectrum bacteria and insect resistance of LecRK-VI.2 in Arabidopsis and LecRK1-3 in rice indicate that Lectin-RLKs prime PTI response to both pathogen and insect attacks by either directly or indirectly perceiving conserved microbe- or insect-derived elicitors or DAMP.

Arabidopsis contains 25 RLKs with EGF-like motif ectodmain, among which wall-associated kinases (WAKs) play key roles in plant immunity shown by previous findings (Brutus et al., 2010; Delteil et al., 2016; Kohorn et al., 2009). Plant cell wall component oligogalacturonides, a well-known class of DAMPs released during pathogen attacks, are sensed by WAK1 in Arabidopsis (Brutus et al., 2010; Decreux and Messiaen, 2005; Decreux et al., 2006). Another
Arabidopsis EGF-like motif-containing RK, WAK2 can bind pectin and activates the mitogen-activated protein kinases (MPK) (Kohorn et al., 2009). Moreover, WAK14, WAK91 and WAK92 are required for quantitative resistance to the rice blast disease (Delteil et al., 2016). These findings indicate that perception of plant cell wall components is uniquely important for plant disease resistance.

\section{OLIGOMERIZATION AS A COMMON MECHA- NISM FOR PRR ACTIVATION}

Ligand-induced oligomerization between RKs and RLKs or RPs and RLKs are a common mechanism for the activation of PRRs. In Arabidopsis, FLS2 and EFR can form heterodimer with co-receptor SERK3/BAK1, an RLK belonging to a small family of RLKs called SERKs with 5 members, after flg22 and elf18 treatment, respectively (Chinchilla et al., 2007; Heese et al., 2007; Schulze et al., 2010; Sun et al., 2013a). The involvement of BAK1 as a co-receptor appears to be common for LRR RKs. Indeed, a recent report showed that Pep1 also induces PEPR1 heterodimerization with BAK1 (Tang et al., 2015). Moreover, phytosulfokine (PSK), a disulfated pentapeptide, promotes PSKR-SERK1/SERK2/BAK1 heterodimerization between PSKR and BAK1 or BAK1 paralogs SERK1 or SERK2 in the regulation of plant development (Wang et al., 2015). BAK1 not only is required for LRR-RKs function, but also for LRR-RP function. Recent evidence indicated that the LRR-RLK suppressor of BIR1 (SOBIR1) as an adaptor interacts with multiple LRR RPs in Arabidopsis (RLP1, RLP23, RLP30 and RLP42) and tomato (Cf, Ve1, and Eix). It is now clear that BAK is also recruited to RP/SOBIR1 complex to regulate immune signaling output following ligand stimulation (Gust and Felix, 2014).

In contrast to LRR-RKs and RPs, LysM-RK and RPs do not seem to require BAK1 for function with one exception (Henty-Ridilla et al., 2013). In rice, chitin induced heterodimerization between CEBiP and CERK1 is necessary for chitin-induced immune activation. Similarly, PGN induces heterodimerization between LYM1/LYM3 and CERK1 in Arabidopsis or LYP4/LYP6 and CERK1 in rice (Gust, 2015). Together, the aforementioned findings indicate that ligand induced oligomerization between RLK-RK or RLK-RP is a universal mechanism for immune activation by plant PRRs.

Protein structure analyses have provided atomic level understanding of ligand-induced activation of RKs. The structures of the ECDs of Arabidopsis FLS2, BRI1, and carrot PSKR LRR-RKs complexed with their cognate co-receptors and ligands have been solved recently (Santiago et al., 2013; Sun et al., 2013a, b; Wang et al., 2015). The structural studies explain previous genetic data and provide mechanistic insight concerning how the receptors recognize their cognate ligands. The ECDs of FLS2, BRI1 and PSKR all adopt a right-hand superhelical structure, which seems to be common to plant 
LRR-RKs (Zhang and Thomma, 2013; Han et al., 2014). Equal proportion of receptor/ligand/co-receptor in the complex of FLS2-flg22-BAK1, BRI1-BL-BAK1, and PSKR-PSK-SERK2 was revealed by crystal structures (Santiago et al., 2013; Sun et al., 2013a, b; Wang et al., 2015). However, the ligands do not induce homo-oligomerization of their receptors (Santiago et al., 2013; Sun et al., 2013a, b; Wang et al., 2015), which is different from animal TLRs (Song and Lee, 2012). Apart from the commonalities, there are obvious differences in activation mechanisms among the three receptor complexes. Flg22 and BL do not induce conformation change of FLS2 and BRI1, and both ligands are directly involved in the formation of heterodimerization by contacting with $\mathrm{N}$-terminus of BAK1 LRR (Santiago et al., 2013; Sun et al., 2013a, b). A protuberance of non-LRR structure called island domain (ID) interrupts ECDs of BRI1 and PSKR (Santiago et al., 2013; Sun et al., 2013b; Wang et al., 2015) (Figure 2). The ID is responsible for ligand binding, which is much larger in BRI1 compared to that in PSKR (Wang et al., 2015). A change of conformation occurs in PSK bound PSKR ${ }^{\mathrm{ID}}$, which is more similar to BRI ${ }^{\mathrm{ID}}$ compared with a free $\mathrm{PSKR}^{\mathrm{ID}}$ (Wang et al., 2015). Contrary to flg22 and BL, PSK does not directly interact with SERK2, the N-terminus of which only interacts with PSK bound PSKR ${ }^{\mathrm{ID}}$ (Wang et al., 2015). As a similar short ID also exists in other RLPs and RLKs, it will be interesting to find whether they adopt the same mechanism to activate receptor complex. The FLS2 LRR domain does not contain an ID. Instead, 14 LRRs of FLS2 directly associate with Flg22 (Sun et al., 2013a). The C-terminal flg22 residue Gly 18 acts as "molecular glue" to mediate interaction between FLS2LRR and BAK1LRR (Sun et al., 2013a).

Although the crystal structures of ECDs perfectly reveal mechanisms by which cognate ligands induce receptor complexes formation, they do not readily explain trans-phosphorylation of the intracellular kinase domain as ectodomain structures do not reveal molecular event in kinase domain. Recent investigation of kinase domain revealed that dimerization supports slight conformational change of the intracellular domain (Yan et al., 2012; Bojar et al., 2014), which may favor the trans-phosphorylation and activation of kinase domain. In all, dimerization of ECDs induced by ligands paves the way for juxtaposition of intracellular kinase domain, which is a general activation strategy of plant RLK/RLPs.

\section{RLCKS LINK PRRS WITH DOWNSTREAM SIG- NALING}

A major challenge to the field of plant immunity is to understand how the activation of PRRs leads to diverse defense responses. Following the activation of PRR complexes, many cellular responses are triggered, including reactive oxygen species (ROS) production, $\mathrm{Ca}^{2+}$ burst, a rapid activation of MPKs and the up-regulation of defense gene expression (Boller and Felix, 2009; Dodds and Rathjen, 2010; Macho and Zipfel, 2014; Monaghan and Zipfel, 2012; $\mathrm{Wu}$ and Zhou, 2013). These early signaling events are responsible for orchestration of diverse defenses that ultimately restrict pathogen progression. In recent years, several receptor-like cytoplasmic kinases (RLCKs) have emerged as central components of PRR complexes that link PRR activation to various early signaling events.

Botrytis-induced kinase 1 (BIK1) and PBS1-like 1 (PBL1), two highly homologous members of RLCK-VII family, act as positive regulator in multiple PRR complexes (Lu et al., 2010;

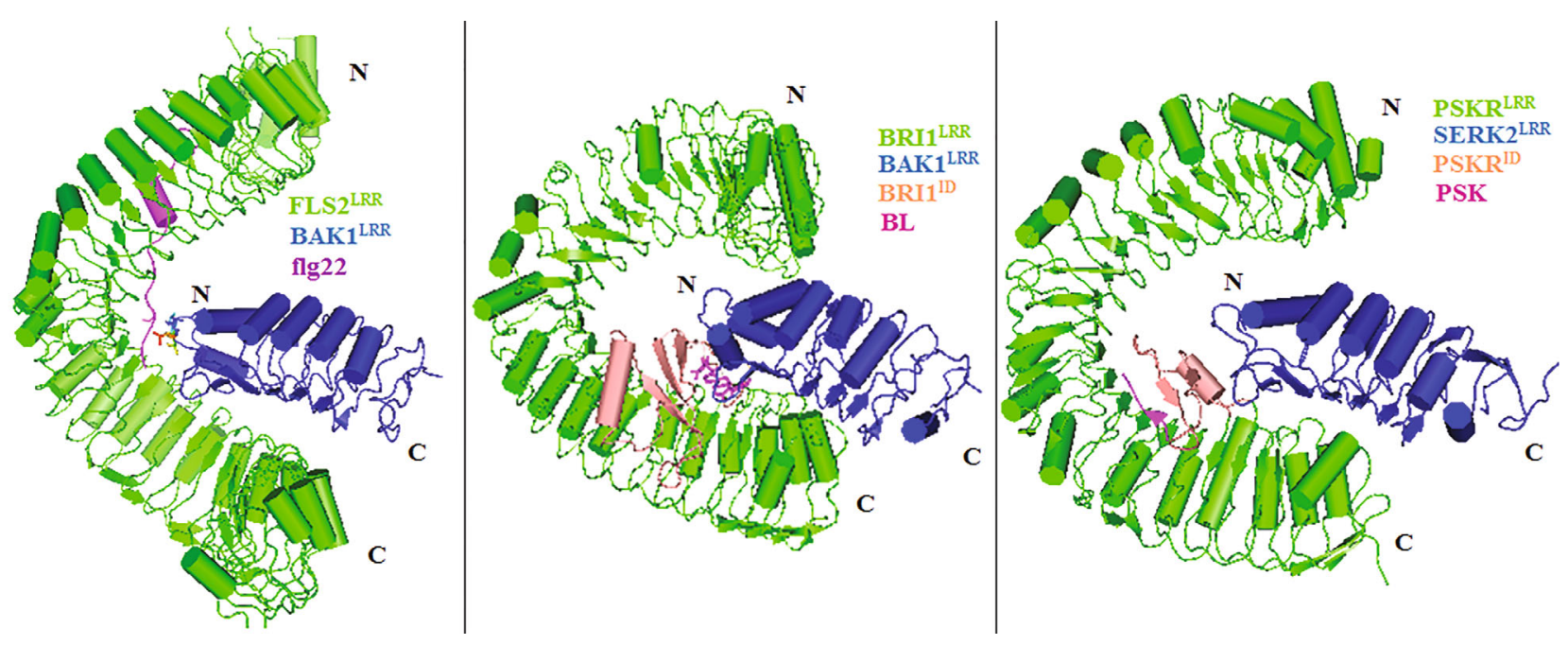

Figure 2 Atomic structures of FLS2LRR-flg22-BAK1LRR, BRI1LRR-BL-BAK1LRR, and PSKRLRR-PSK-SERK2LRR. The ECDs of FLS2, BRI1, and PSKR form the right-hand superhelical structure. Flg22 interacts with 14 LRRs of the concave of FLS2. C-terminal residue Gly18 of flg22 directly mediates $\mathrm{N}$-terminus of BAK1LRR interaction. BL and PSK bind the island domain (ID) of BRI1 and PSKR respectively. PSK induces conformational change of PSKR ID to recruit SERK2 to form stable PSKR-SERK2 complex. 
Zhang et al., 2010). BIK1 and PBL1 can directly associate with unstimulated FLS2, EFR, CERK1 and PEPR1 (Zhang et al., 2010; Liu et al., 2013b). Accordingly, the bik1 pbl1 double mutant exhibits reduced immune responses triggered by multiple PAMPs, such as ROS production, defense gene expression, callose deposition, and transient influx of calcium ion from the apoplast, and is severely compromised in nonadapted bacterial pathogen and pathogenic fungus Botrytis cinerea (Li et al., 2014b; Lu et al., 2010; Veronese et al., 2006; Zhang et al., 2010). Furthermore, both Xanthomonas effector AvrAC and Pseudomonas effector AvrPphB can specifically target Arabidopsis BIK1 and related PBLs, resulting in reduced kinase activity and inhibition of plant immunity (Feng et al., 2012; Zhang et al., 2010). The fact that unrelated effectors from completely different pathogens target BIK1/PBLs further highlights the importance of BIK1/PBLs in plant immunity.

In rice, RLCK185 and RLCK176, two members of BIK1 family, directly interacts with CERK1 to mediate chitin- and PGN-induced plant immunity (Ao et al., 2014; Yamaguchi et al., 2013). Similarly, PBL27, an Arabidopsis ortholog of RLCK185, also interacts with CERK1 and contributes to chitin-induced immunity but not flg22-induced immunity (Shinya et al., 2014). In addition, BR-signaling kinase 1 (BSK1), associates with FLS2 and is required for flg22-induced ROS burst (Shi et al., 2013). Recently, another RLCK-VII family member PCRK1 was reported to play important roles during flg22-, elf18- and pep1-triggered immunity, although it is unknown whether it interacts with PRRs (Sreekanta et al., 2015). So far, the above mentioned findings suggest that while some RLCKs associate with multiple PRRs, others may interact with one or a few specific PRRs. It will be interesting to investigate whether different RLCKs regulate distinct or overlapping downstream components during immune signaling.

Transient $\mathrm{Ca}^{2+}$ influx is one critical early cellular response after FLS2, EFR and PEPR activation (Lecourieux et al., 2006; Qi et al., 2010). The calcium as a second messenger, almost participates in all the defense responses (Lecourieux et al., 2006). Recent work showed that BIK1 and PBL1 are required for the flg22-induced calcium influx, which is required for the activation of RbohD to regulate ROS production (Li et al., 2014b; Ranf et al., 2014). How PRR complexes activate transient $\mathrm{Ca}^{2+}$ influx is unknown. The fact that BIK1 and PBL1 are required for the flg22-idnuced calcium influx suggest that phosphorylation of an unknown calcium channel may lead to the opening of the $\mathrm{Ca}^{2+}$ channel.

ROS burst is another cellular response mediated by multiple PRRs. Recently, respiratory burst oxidase homolog $\mathrm{D}$ (RbohD), a membrane-localized enzyme responsible for transient ROS production (Torres et al., 2002), was identified as the first substrate of BIK1 (Kadota et al., 2014;
Li et al., 2014b). RbohD directly associates with FLS2 and other PRR complexes before activation. Upon stimulation by PAMPs, RbohD is phosphorylated directly by the activated BIK1, and then dissociates from the PRR complex, allowing it to be activated by other signals, such as calcium (Kadota et al., 2014; Li et al., 2014b; Ma, 2014).

Recently, it was shown that heterotrimeric $G$ proteins composed of Ga protein XLG2, G $\beta$ protein AGB1, and $\mathrm{G} \gamma$ proteins AGG1 and AGG2 are required for ROS production and disease resistance mediated by FLS2, EFR, and CERK1 (Liu et al., 2013a; Maruta et al., 2015). Most recent report showed that the $G$ proteins directly interact with FLS2-BIK1 receptor complex. Upon activation of the FLS2-BIK1 complex by flg22, BIK1 directly phosphorylates the $\mathrm{N}$ terminus of XLG2 to enhance ROS production (Liang et al., 2016). However, the phosphorylated XLG2 did not affect XLG2-BIK1 interaction or BIK1 stability in the post-activation state. Considering that XLG2 associates with $\mathrm{RbohD}$ constitutively and that RbohD activity is regulated by binding to $\mathrm{Ca}^{2+}$ and phosphatidic acid (PA), and phosphorylation by BIK1 and CPK5 (Dubiella et al., 2013; Kadota et al., 2014; Li et al., 2014b; Liang et al., 2016; Zhang et al., 2009), it will be interesting to determine whether the phosphorylated XLG2 modulates these processes.

After PRR complexes are activated, MPK activation occurs within 1-2 min and then reaches a peak at 10-15 min, which plays crucial roles in multiple defense responses including cell death, defense gene expression and stomatal closure (Meng and Zhang, 2013). Although it has not been genetically established, multiple lines evidence support a role of BIK1/PBLs in MPK activation. For example, although the bik1 pbl1 mutant exhibited normal flg22-induced activation of MPKs (Feng et al., 2012), the Xanthomonas campestris effector protein AvrAC, which specifically inhibits multiple PBLs by uridylylation, severely inhibited flg22-induced MPK activation (Feng et al., 2012). This suggests that additional PBLs are required for MPK activation, although it does not rule out the possibility that new components other than RLCKs are involved. In the future, it will be important to determine whether uncharacterized RLCKs play a specific role in MPK activation or multiple RLCKs act redundantly to control MPK activation.

\section{DYNAMIC REGULATION OF PRR COM- PLEXES}

Rapid and robust activation of plant immune signaling is crucial for plants to mount effective defenses against invading pathogens. However, excessive immune signaling can be detrimental to plants. Thus the composition, activity, and abundance of PRR complexes must be subject to tight regulation both before and after immune activation.

An important regulatory aspect is to control PRR com- 
plexes formation prior to ligand perception. For example, recent findings showed that LRR-RLK BIR2, a pseudokinase, prevents the PRRs-BAK1 complex formation at resting state (Halter et al, 2014a). BIR2 associates with BAK1 constitutively to prevent the interactions of BAK1 with adjacent PRRs before PAMPs perception. After ligands perception, BIR2 is released from BAK1 and results in PRRs and BAK1 interaction and immune activation rapidly (Blaum et al., 2014; Halter et al., 2014a, b). In addition, another LRR-RLK BIR1 also interacts with BAK1 to negatively regulate plant defense responses (Gao et al., 2009). In contrast to BIR2, BIR1 is an active kinase and the kinase activity is partially required for its function, although they belong to the same subfamily and both birl and bir2 mutant have a cell death phenotype (Gao et al., 2009; Halter et al., 2014a, b). This suggests that BIR1 and BAK1 complex regulates plant immunity likely via a different molecular mechanism, such as perception of an unknown signal.

PRR complex stability is another important regulatory mechanism. Recent advances showed that BIK1 stability is known to be regulated by $26 \mathrm{~S}$ proteasome pathway and that CPK28 facilitates BIK1 degradation to negatively regulate immunity in the pre-activation state (Monaghan et al., 2014). More recent studies showed that, in addition to regulating ROS production in the post-activation state, the heterotrimeric $\mathrm{G}$ proteins are directly coupled to FLS2-BIK1 receptor complex to stabilize the BIK1 protein, also in the pre-activation state (Liang et al., 2016). This allows plants to initiate robust immune responses once stimulated by flg22 (Liang et al., 2016). The findings indicate that CPK28 and $\mathrm{G}$ proteins control BIK1 turn-over oppositely by $26 \mathrm{~S}$ proteasome pathway, ensuring optimum level of BIK1 for immune activation. Since CPK28 and the G proteins both regulate $\mathrm{BIK} 1$ in the pre-activation state, it is possible that they regulate BIK1 ubiquitination by the same, unknown E3 ligases.

In addition to pre-activation, PRR complex stability also is regulated after stimulation by PAMPs. For example, FLS2 is subject to degradation by the $26 \mathrm{~S}$ proteasome pathway after flg22 perception to attenuate immune signaling (Lu et al., 2011). FLS2 is ubiquitinated by two U-Box E3 ligases PUB12 and PUB13 for degradation. PUB12 and PUB13 constitutively interact with BAK1 and are recruited to the FLS2 after flg22 perception, resulting in an flg22-induced ubiquitination and degradation of FLS2 but not BAK1 (Lu et al., 2011), which is crucial for preventing prolonged immune activation. These findings shed light on one important mechanism of how E3 ligases attenuate immune signaling after the PRR activation.

Ligand-induced endocytosis is another regulatory mechanism controlling PRR immune activation. After flg22 elicitation, FLS2 is subject to endocytosis and degradation within $1 \mathrm{~h}$, which may prevent continuous immune activation (Smith et al., 2014). There is no evidence that FLS2 ubiquitination by PUB12/13 contributes to FLS2 endocytosis (Li et al., 2014a). The stimulated cells are replenished with newly synthesized FLS2 to restore flg22-sensing capability within $2 \mathrm{~h}$ (Smith et al., 2014). FLS2 endocytosis may also serve to promote flg22-signaling competency. For example, FLS2 co-localizes with the endosomal sorting complex required for transport (ESCRT)-I subunits at endosomes after flg22 perception, resulting in FLS2 endosomal sorting (Spallek et al., 2013). The ESCRT-I components VSP37-1 and VSP28-2 are required for not only FLS2 endocytosis, but also flg22-induced stomatal immunity (Spallek et al., 2013). Moreover, stomatal cytokinesis defective 1 (SCD1), which functions in clathrin-mediated endocytosis (McMichael et al., 2013), was also found as an FLS2 interaction partner required for flg22-induced ROS burst (Korasick et al., 2010). These findings raise interesting possibility that the activated PRR complex is mobilized to intracellular compartments to activate various downstream responses.

\section{CONCLUDING REMARKS}

Increasing evidences support that the RLK and RLP super families play a crucial role in the perception of diverse microbial and endogenous patterns, forming a powerful surveillance system at the cell surface against invading microbes and insects. We are far from that knowing the complete repertoire of PRRs in a plant species and ligands they perceive. A daunting task will be to assign biological and biochemical functions to the vast majority of RLKs and RLPs that are functionally unknown, particularly those involved in plant immunity.

RLK-RK or RLK-RP oligomerization induced by cognate ligand is a common mechanism for the activation of PRRs. The PRRs, as core components, can recruit RLCKs, substrates of RLCKs, and other regulators to form dynamic plant PRR immune complexes, allowing robust but controlled intracellular signaling in the face of pathogen attacks without unwanted effect on growth and development under normal conditions. An important question is how different components are organized in the PRR complex, whether they reside in the same complex or different complexes. Major gaps remain in our knowledge concerning regulation of early immune signaling events, such as the control of calcium burst and MPK activation. Future challenge is to identify new components linking PRR complexes and activation of various key signaling events.

Compliance and ethics The author(s) declare that they have no conflict of interest. 
Acknowledgements We apologize to all colleagues whose work is not cited due to space limitations. This work was supported by Chinese Ministry of Science and Technology (2015CB910201), and Chinese Academy of Sciences Strategic Priority Research Program (XDB11020200).

Albert, I., Böhm, H., Albert, M., Feiler, C.E., Imkampe, J., Wallmeroth, N., Brancato, C., Raaymakers, T.M., Oome, S., Zhang, H., Krol, E., Grefen, C., Gust, A.A., Chai, J., Hedrich, R., Van den Ackerveken, G., and Nürnberger, T. (2015). An RLP23-SOBIR1-BAK1 complex mediates NLP-triggered immunity. Nat Plants 1, 15140.

Amor, B.B., Shaw, S.L., Oldroyd, G.E.D., Maillet, F., Penmetsa, R.V., Cook, D., Long, S.R., Denarie, J., and Gough, C. (2003). The NFP locus of Medicago truncatula controls an early step of Nod factor signal transduction upstream of a rapid calcium flux and root hair deformation. Plant J 34, 495-506.

Antolín-Llovera, M., Ried, M.K., Binder, A., and Parniske, M. (2012). Receptor kinase signaling pathways in plant-microbe interactions. Annu Rev Phytopathol 50, 451-473.

Ao, Y., Li, Z., Feng, D., Xiong, F., Liu, J., Li, J.F., Wang, M., Wang, J., Liu, B., and Wang, H.B. (2014). OsCERK1 and OsRLCK176 play important roles in peptidoglycan and chitin signaling in rice innate immunity. Plant J 80, 1072-1084

Bauer, Z., Gomez-Gomez, L., Boller, T., and Felix, G. (2001). Sensitivity of different ecotypes and mutants of Arabidopsis thaliana toward the bacterial elicitor flagellin correlates with the presence of receptor-binding sites. J Biol Chem 276, 45669-45676.

Blaum, B.S., Mazzotta, S., Nöldeke, E.R., Halter, T., Madlung, J., Kemmerling, B., and Stehle, T. (2014). Structure of the pseudokinase domain of BIR2, a regulator of BAK1-mediated immune signaling in Arabidopsis. J Struct Biol 186, 112-121.

Bojar, D., Martinez, J., Santiago, J., Rybin, V., Bayliss, R., and Hothorn, M. (2014). Crystal structures of the phosphorylated BRI1 kinase domain and implications for brassinosteroid signal initiation. Plant J 78, 31-43.

Boller, T., and Felix, G. (2009). A renaissance of elicitors: perception of microbe-associated molecular patterns and danger signals by pattern-recognition receptors. Annu Rev Plant Biol 60, 379-406.

Brutus, A., Sicilia, F., Macone, A., Cervone, F., and De Lorenzo, G. (2010). A domain swap approach reveals a role of the plant wall-associated kinase 1 (WAK1) as a receptor of oligogalacturonides. Proc Natl Acad Sci USA 107, 9452-9457.

Cao, Y., Liang, Y., Tanaka, K., Nguyen, C.T., Jedrzejczak, R.P., Joachimiak, A., and Stacey, G. (2014). The kinase LYK5 is a major chitin receptor in Arabidopsis and forms a chitin-induced complex with related kinase CERK1. Elife.

Chamaillard, M., Hashimoto, M., Horie, Y., Masumoto, J., Qiu, S., Saab, L., Ogura, Y., Kawasaki, A., Fukase, K., Kusumoto, S., Valvano, M.A., Foster, S.J., Mak, T.W., Nuñez, G., and Inohara, N. (2003). An essential role for NOD1 in host recognition of bacterial peptidoglycan containing diaminopimelic acid. Nat Immunol 4, 702-707.

Chinchilla, D., Zipfel, C., Robatzek, S., Kemmerling, B., Nürnberger, T., Jones, J.D.G., Felix, G., and Boller, T. (2007). A flagellin-induced complex of the receptor FLS2 and BAK1 initiates plant defence. Nature 448, 497-500.

Choi, J., Tanaka, K., Cao, Y., Qi, Y., Qiu, J., Liang, Y., Lee, S.Y., and Stacey, G. (2014). Identification of a plant receptor for extracellular ATP. Science 343, 290-294

de Jonge, R., Bolton, M.D., and Thomma, B.P. (2011). How filamentous pathogens co-opt plants: the ins and outs of fungal effectors. Curr Opin Plant Biol 14, 400-406.

Decreux, A., and Messiaen, J. (2005). Wall-associated kinase WAK1 interacts with cell wall pectins in a calcium-induced conformation. Plant Cell Physiol 46, 268-278.

Decreux, A., Thomas, A., Spies, B., Brasseur, R., Cutsem, P., and Messiaen, J. (2006). In vitro characterization of the homogalacturonan-binding domain of the wall-associated kinase WAK1 using site-directed mutagene- sis. Phytochemistry 67, 1068-1079.

Delteil, A., Gobbato, E., Cayrol, B., Estevan, J., Michel-Romiti, C., Dievart, A., Kroj, T., and Morel, J.B. (2016). Several wall-associated kinases participate positively and negatively in basal defense against rice blast fungus. BMC Plant Biol 16, 263.

Dixon, M.S., Jones, D.A., Keddie, J.S., Thomas, C.M., Harrison, K., and Jones, J.D.G. (1996). The tomato Cf-2 disease resistance locus comprises two functional genes encoding leucine-rich repeat proteins. Cell $84,451-459$.

Dodds, P.N., and Rathjen, J.P. (2010). Plant immunity: towards an integrated view of plant-pathogen interactions. Nat Rev Genet 11, 539-548.

Dziarski, R., and Gupta, D. (2010). Review: mammalian peptidoglycan recognition proteins (PGRPs) in innate immunity. Innate Immun 16, 168-174.

Dubiella, U., Seybold, H., Durian, G., Komander, E., Lassig, R., Witte, C.P., Schulze, W.X., and Romeis, T. (2013). Calcium-dependent protein kinase/NADPH oxidase activation circuit is required for rapid defense signal propagation. Proc Natl Acad Sci USA 110, 8744-8749.

Erbs, G., Silipo, A., Aslam, S., De Castro, C., Liparoti, V., Flagiello, A., Pucci, P., Lanzetta, R., Parrilli, M., Molinaro, A., Newman, M.A., and Cooper, R.M. (2008). Peptidoglycan and muropeptides from Pathogens Agrobacterium and Xanthomonas elicit plant innate immunity: structure and activity. Chem Biol 15, 438-448.

Feng, F., Yang, F., Rong, W., Wu, X., Zhang, J., Chen, S., He, C., and Zhou, J.M. (2012). A Xanthomonas uridine 5'-monophosphate transferase inhibits plant immune kinases. Nature 485, 114-118.

Fritz-Laylin, L.K. (2005). Phylogenomic analysis of the receptor-like proteins of rice and Arabidopsis. Plant Physiol 138, 611-623.

Gao, M., Wang, X., Wang, D., Xu, F., Ding, X., Zhang, Z., Bi, D., Cheng, Y.T., Chen, S., Li, X., and Zhang, Y. (2009). Regulation of cell death and innate immunity by two receptor-like kinases in Arabidopsis. Cell Host Microbe 6, 34-44.

Girardin, S.E. (2003). Nod2 is a general sensor of peptidoglycan through muramyl dipeptide (MDP) detection. J Biol Chem 278, 8869-8872.

Gómez-Gómez, L., and Boller, T. (2000). FLS2: an LRR receptor-like kinase involved in the perception of the bacterial elicitor flagellin in Arabidopsis. Mol Cell 5, 1003-1011.

Gust, A.A., and Zipfel, C. (2015). Peptidoglycan perception in plants. PLoS Pathog 11, e1005275.

Gust, A.A., and Felix, G. (2014). Receptor like proteins associate with SOBIR1-type of adaptors to form bimolecular receptor kinases. Curr Opin Plant Biol 21, 104-111.

Gust, A.A., Biswas, R., Lenz, H.D., Rauhut, T., Ranf, S., Kemmerling, B., Gotz, F., Glawischnig, E., Lee, J., Felix, G., and Nurnberger, T. (2007). Bacteria-derived peptidoglycans constitute pathogen-associated molecular patterns triggering innate immunity in Arabidopsis. J Biol Chem 282, 32338-32348.

Gust, A.A., Willmann, R., Desaki, Y., Grabherr, H.M., and Nürnberger, T. (2012). Plant LysM proteins: modules mediating symbiosis and immunity. Trends Plant Sci 17, 495-502.

Han, Z., Sun, Y., and Chai, J. (2014). Structural insight into the activation of plant receptor kinases. Curr Opin Plant Biol 20, 55-63.

Hayashi, F., Smith, K.D., Ozinsky, A., Hawn, T.R., Yi, E.C., Goodlett, D.R., Eng, J.K., Akira, S., Underhill, D.M., and Aderem, A. (2001). The innate immune response to bacterial flagellin is mediated by Toll-like receptor 5. Nature 410, 1099-1103.

Halter, T., Imkampe, J., Mazzotta, S., Wierzba, M., Postel, S., Bücherl, C., Kiefer, C., Stahl, M., Chinchilla, D., Wang, X., Nürnberger, T., Zipfel, C., Clouse, S., Borst, J.W., Boeren, S., de Vries, S.C., Tax, F., and Kemmerling, B. (2014a). The leucine-rich repeat receptor kinase BIR2 is a negative regulator of BAK1 in plant immunity. Curr Biol 24, 134-143.

Halter, T., Imkampe, J., Blaum, B.S., Stehle, T., and Kemmerling, B. (2014b). BIR2 affects complex formation of BAK1 with ligand binding receptors in plant defense. Plant Signal Behav 9, e28944.

Heese, A., Hann, D.R., Gimenez-Ibanez, S., Jones, A.M.E., He, K., Li, J., Schroeder, J.I., Peck, S.C., and Rathjen, J.P. (2007). The receptor-like 
kinase SERK3/BAK1 is a central regulator of innate immunity in plants. Proc Natl Acad Sci USA 104, 12217-12222.

Henty-Ridilla, J.L., Shimono, M., Li, J., Chang, J.H., Day, B., Staiger, C.J., and Zhou, J.M. (2013). The plant actin cytoskeleton responds to signals from microbe-associated molecular patterns. PLoS Pathog 9, e1003290.

Hou, S., Wang, X., Chen, D., Yang, X., Wang, M., Turrà, D., Di Pietro, A., Zhang, W., and Tyler, B. (2014). The secreted peptide PIP1 amplifies immunity through receptor-like kinase 7. PLoS Pathog 10, e1004331.

Huffaker, A., and Ryan, C.A. (2007). Endogenous peptide defense signals in Arabidopsis differentially amplify signaling for the innate immune response. Proc Natl Acad Sci USA 104, 10732-10736.

Jehle, A.K., Lipschis, M., Albert, M., Fallahzadeh-Mamaghani, V., Furst, U., Mueller, K., and Felix, G. (2013). The receptor-like protein ReMAX of Arabidopsis detects the microbe-associated molecular pattern eMax from Xanthomonas. Plant Cell 25, 2330-2340.

Jones, J.D.G., and Dangl, J.L. (2006). The plant immune system. Nature 444, 323-329.

Joosten, M., and de Wit, P. (1999). THE TOMATO-CLADOSPORIUM FULVUM INTERACTION: a versatile experimental system to study plant-pathogen interactions. Annu Rev Phytopathol 37, 335-367.

Kadota, Y., Sklenar, J., Derbyshire, P., Stransfeld, L., Asai, S., Ntoukakis, V., Jones, J.D., Shirasu, K., Menke, F., Jones, A., and Zipfel, C. (2014). Direct regulation of the NADPH oxidase RBOHD by the PRR-associated kinase BIK1 during plant immunity. Mol Cell 54, 43-55.

Kaku, H., Nishizawa, Y., Ishii-Minami, N., Akimoto-Tomiyama, C., Dohmae, N., Takio, K., Minami, E., and Shibuya, N. (2006). Plant cells recognize chitin fragments for defense signaling through a plasma membrane receptor. Proc Natl Acad Sci USA 103, 11086-11091.

Knirel, Y.A., Bystrova, O.V., Kocharova, N.A., Zähringer, U., and Pier, G.B. (2006). Conserved and variable structural features in the lipopolysaccharide of Pseudomonas aeruginosa. J Endotoxin Res 12, 324-336.

Kohorn, B.D., Johansen, S., Shishido, A., Todorova, T., Martinez, R., Defeo, E., and Obregon, P. (2009). Pectin activation of MAP kinase and gene expression is WAK2 dependent. Plant J 60, 974-982.

Korasick, D.A., McMichael, C., Walker, K.A., Anderson, J.C., Bednarek, S.Y., and Heese, A. (2010). Novel functions of stomatal cytokinesis-defective 1 (SCD1) in innate immune responses against bacteria. J Biol Chem 285, 23342-23350.

Krol, E., Mentzel, T., Chinchilla, D., Boller, T., Felix, G., Kemmerling, B., Postel, S., Arents, M., Jeworutzki, E., Al-Rasheid, K.A.S., Becker, D., and Hedrich, R. (2010). Perception of the Arabidopsis danger signal peptide 1 involves the pattern recognition receptor AtPEPR1 and its close homologueAt PEPR2. J Biol Chem 285, 13471-13479.

Kruger, J. (2002). A tomato cysteine protease required for Cf-2-dependent disease resistance and suppression of autonecrosis. Science 296, 744-747.

Kunze, G. (2004). The $\mathrm{N}$ terminus of bacterial elongation factor Tu elicits innate immunity in Arabidopsis plants. Plant Cell 16, 3496-3507.

Kurata, S. (2010). Extracellular and intracellular pathogen recognition by Drosophila PGRP-LE and PGRP-LC. Int Immunol 22, 143-148.

Lecourieux, D., Ranjeva, R., and Pugin, A. (2006). Calcium in plant defence-signalling pathways. New Phytol 171, 249-269.

Li, B., Lu, D., and Shan, L. (2014a). Ubiquitination of pattern recognition receptors in plant innate immunity. Mol Plant Pathol 15, 737-746.

Li, J., and Chory, J. (1997). A putative leucine-rich repeat receptor kinase involved in brassinosteroid signal transduction. Cell 90, 929-938.

Li, L., Li, M., Yu, L., Zhou, Z., Liang, X., Liu, Z., Cai, G., Gao, L., Zhang, X., Wang, Y., Chen, S., and Zhou, J.M. (2014b). The FLS2-associated kinase BIK1 directly phosphorylates the NADPH oxidase RbohD to control plant immunity. Cell Host Microbe 15, 329-338.

Liang, X., Ding, P., Lian, K, Wang, J., Ma, M., Li, L., Li, L., Li, M., Zhang, X., Chen, S., Zhang, Y., and Zhou, J.M. (2016). Arabidopsis heterotrimeric $\mathrm{G}$ proteins regulate immunity by directly coupling to the FLS2 receptor. Elife 5, e13568.

Liebrand, T.W.H., van den Burg, H.A., and Joosten, M.H.A.J. (2014). Two for all: receptor-associated kinases SOBIR1 and BAK1. Trends Plant
Sci 19, 123-132.

Limpens, E. (2003). LysM domain receptor kinases regulating rhizobial Nod factor-induced infection. Science 302, 630-633.

Liu, B., Li, J.F., Ao, Y., Qu, J., Li, Z., Su, J., Zhang, Y., Liu, J., Feng, D., Qi, K., He, Y., Wang, J., and Wang, H.B. (2012a). Lysin motif-containing proteins LYP4 and LYP6 play dual roles in peptidoglycan and chitin perception in rice innate immunity. Plant Cell 24, 3406-3419.

Liu, J., Ding, P., Sun, T., Nitta, Y., Dong, O., Huang, X., Yang, W., Li, X., Botella, J.R., and Zhang, Y. (2013a). Heterotrimeric G proteins serve as a converging point in plant defense signaling activated by multiple receptor-like kinases. Plant Physiol 161, 2146-2158.

Liu, T., Liu, Z., Song, C., Hu, Y., Han, Z., She, J., Fan, F., Wang, J., Jin, C., Chang, J., Zhou, J.M., and Chai, J. (2012b). Chitin-induced dimerization activates a plant immune receptor. Science 336, 1160-1164.

Liu, Y., Wu, H., Chen, H., Liu, Y., He, J., Kang, H., Sun, Z., Pan, G., Wang, Q., Hu, J., Zhou, F., Zhou, K., Zheng, X., Ren, Y., Chen, L., Wang, Y., Zhao, Z., Lin, Q., Wu, F., Zhang, X., Guo, X., Cheng, X., Jiang, L., Wu, C., Wang, H., and Wan, J. (2014). A gene cluster encoding lectin receptor kinases confers broad-spectrum and durable insect resistance in rice. Nat Biotechnol 33, 301-305.

Liu, Z., Wu, Y., Yang, F., Zhang, Y., Chen, S., Xie, Q., Tian, X., and Zhou, J.M. (2013b). BIK1 interacts with PEPRs to mediate ethylene-induced immunity. Proc Natl Acad Sci USA 110, 6205-6210.

Lu, D., Wu, S., Gao, X., Zhang, Y., Shan, L., and He, P. (2010). A receptor-like cytoplasmic kinase, BIK1, associates with a flagellin receptor complex to initiate plant innate immunity. Proc Natl Acad Sci USA 107, 496-501.

Lu, D., Lin, W., Gao, X., Wu, S., Cheng, C., Avila, J., Heese, A., Devarenne, T.P., He, P., and Shan, L. (2011). Direct ubiquitination of pattern recognition receptor FLS2 attenuates plant innate immunity. Science 332, 1439-1442.

Luderer, R., Takken, F.L.W., Wit, P.J.G.M., and Joosten, M.H.A.J. (2002). Cladosporium fulvum overcomes $\mathrm{Cf}-2$-mediated resistance by producing truncated AVR2 elicitor proteins. Mol Microbiol 45, 875-884.

Ma, W. (2014). From pathogen recognition to plant immunity: BIK1 cROSses the divide. Cell Host Microbe 15, 253-254.

Macho, A.P., and Zipfel, C. (2014). Plant PRRs and the activation of innate immune signaling. Mol Cell 54, 263-272.

Madsen, E.B., Madsen, L.H., Radutoiu, S., Olbryt, M., Rakwalska, M., Szczyglowski, K., Sato, S., Kaneko, T., Tabata, S., Sandal, N., and Stougaard, J. (2003). A receptor kinase gene of the LysM type is involved in legumeperception of rhizobial signals. Nature 425, 637-640.

Maillet, F., Poinsot, V., André, O., Puech-Pagès, V., Haouy, A., Gueunier, M., Cromer, L., Giraudet, D., Formey, D., Niebel, A., Martinez, E.A., Driguez, H., Bécard, G., and Dénarié, J. (2011). Fungal lipochitooligosaccharide symbiotic signals in arbuscular mycorrhiza. Nature 469, $58-63$.

Maruta, N., Trusov, Y., Brenya, E., Parekh, U., and Botella, J.R. (2015). Membrane-localized extra-large $\mathrm{G}$ proteins and $\mathrm{Gbg}$ of the heterotrimeric $\mathrm{G}$ proteins form functional complexes engaged in plant immunity in $\mathrm{Ara}$ bidopsis. Plant Physiol 167, 1004-1016.

McMichael, C.M., Reynolds, G.D., Koch, L.M., Wang, C., Jiang, N., Nadeau, J., Sack, F.D., Gelderman, M.B., Pan, J., and Bednarek, S.Y. (2013). Mediation of clathrin-dependent trafficking during cytokinesis and cell expansion by Arabidopsis STOMATAL CYTOKINESIS DEFECTIVE proteins. Plant Cell 25, 3910-3925.

Meng, X., and Zhang, S. (2013). MAPK cascades in plant disease resistance signaling. Annu Rev Phytopathol 51, 245-266.

Miya, A., Albert, P., Shinya, T., Desaki, Y., Ichimura, K., Shirasu, K., Narusaka, Y., Kawakami, N., Kaku, H., and Shibuya, N. (2007). CERK1, a LysM receptor kinase, is essential for chitin elicitor signaling in $\mathrm{Ara}$ bidopsis. Proc Natl Acad Sci USA 104, 19613-19618.

Monaghan, J., and Zipfel, C. (2012). Plant pattern recognition receptor complexes at the plasma membrane. Curr Opin Plant Biol 15, 349-357.

Monaghan, J., Matschi, S., Shorinola, O., Rovenich, H., Matei, A., Segonzac, C., Malinovsky, F.G., Rathjen, J.P., MacLean, D., Romeis, T., and 
Zipfel, C. (2014). The calcium-dependent protein kinase CPK28 buffers plant immunity and regulates BIK1 turnover. Cell Host Microbe 16, 605-615.

Morris, E.R., and Walker, J.C. (2003). Receptor-like protein kinases: the keys to response. Curr Opin Plant Biol 6, 339-342.

Nürnberger, T., Brunner, F., Kemmerling, B., and Piater, L. (2004). Innate immunity in plants and animals: striking similarities and obvious differences. Immunol Rev 198, 249-266.

Op den Camp, R., Streng, A., De Mita, S., Cao, Q., Polone, E., Liu, W., Ammiraju, J.S.S., Kudrna, D., Wing, R., Untergasser, A., Bisseling, T., and Geurts, R. (2011). LysM-type mycorrhizal receptor recruited for rhizobium symbiosis in nonlegume Parasponia. Science 331, 909-912.

Park, B.S., Song, D.H., Kim, H.M., Choi, B.S., Lee, H., and Lee, J.O. (2009). The structural basis of lipopolysaccharide recognition by the TLR4-MD-2 complex. Nature 458, 1191-1195.

Petutschnig, E.K., Jones, A.M.E., Serazetdinova, L., Lipka, U., and Lipka, V. (2010). The lysin motif receptor-like kinase (LysM-RLK) CERK1 is a major chitin-binding protein in Arabidopsis thaliana and subject to chitin-induced phosphorylation. J Biol Chem 285, 28902-28911.

Pruitt, R.N., Schwessinger, B., Joe, A., Thomas, N., Liu, F., Albert, M., Robinson, M.R., Chan, L.J.G., Luu, D.D., Chen, H., Bahar, O., Daudi, A., De Vleesschauwer, D., Caddell, D., Zhang, W., Zhao, X., Li, X., Heazlewood, J.L., Ruan, D., Majumder, D., Chern, M., Kalbacher, H., Midha, S., Patil, P.B., Sonti, R.V., Petzold, C.J., Liu, C.C., Brodbelt, J.S., Felix, G., and Ronald, P.C. (2015). The rice immune receptor XA21 recognizes a tyrosine-sulfated protein from a Gram-negative bacterium. Sci Adv 1, e1500245-e1500245.

Qi, Z., Verma, R., Gehring, C., Yamaguchi, Y., Zhao, Y., Ryan, C.A., and Berkowitz, G.A. (2010). $\mathrm{Ca}^{2+}$ signaling by plant Arabidopsis thaliana Pep peptides depends on AtPepR1, a receptor with guanylyl cyclase activity, and cGMP-activated $\mathrm{Ca}^{2+}$ channels. Proc Natl Acad Sci USA 107, 21193-21198.

Radutoiu, S., Madsen, L.H., Madsen, E.B., Felle, H.H., Umehara, Y., Grønlund, M., Sato, S., Nakamura, Y., Tabata, S., Sandal, N., and Stougaard, J. (2003). Plant recognition of symbiotic bacteria requires two LysM receptor-like kinases. Nature 425, 585-592.

Ranf, S., Eschen-Lippold, L., Fröhlich, K., Westphal, L., Scheel, D., and Lee, J. (2014). Microbe-associated molecular pattern-induced calcium signaling requires the receptor-like cytoplasmic kinases, PBL1 and BIK1. BMC Plant Biol 14, 379.

Ranf, S., Gisch, N., Schäffer, M., Illig, T., Westphal, L., Knirel, Y.A., Sánchez-Carballo, P.M., Zähringer, U., Hückelhoven, R., Lee, J., and Scheel, D. (2015). A lectin S-domain receptor kinase mediates lipopolysaccharide sensing in Arabidopsis thaliana. Nat Immunol 16, 426-433.

Rooney, H.C.E. (2005). Cladosporium Avr2 inhibits tomato Rer3 protease required for Cf-2-dependent disease resistance. Science 308, 1783-1786.

Ross, A., Yamada, K., Hiruma, K., Yamashita-Yamada, M., Lu, X., Takano, Y., Tsuda, K., and Saijo, Y. (2014). The Arabidopsis PEPR pathway couples local and systemic plant immunity. EMBO J 33, 62-75.

Santiago, J., Henzler, C., and Hothorn, M. (2013). Molecular mechanism for plant steroid receptor activation by somatic embryogenesis Co-receptor kinases. Science 341, 889-892.

Schulze, B., Mentzel, T., Jehle, A.K., Mueller, K., Beeler, S., Boller, T., Felix, G., and Chinchilla, D. (2010). Rapid heteromerization and phosphorylation of ligand-activated plant transmembrane receptors and their associated kinase BAK1. J Biol Chem 285, 9444-9451.

Shi, H., Shen, Q., Qi, Y., Yan, H., Nie, H., Chen, Y., Zhao, T., Katagiri, F., and Tang, D. (2013). BR-SIGNALING KINASE1 physically associates with FLAGELLIN SENSING2 and regulates plant innate immunity in Arabidopsis. Plant Cell 25, 1143-1157.

Shimizu, T., Nakano, T., Takamizawa, D., Desaki, Y., Ishii-Minami, N., Nishizawa, Y., Minami, E., Okada, K., Yamane, H., Kaku, H., and Shibuya, N. (2010). Two LysM receptor molecules, CEBiP and OsCERK1, cooperatively regulate chitin elicitor signaling in rice. Plant J 64, 204-214.

Shinya, T., Motoyama, N., Ikeda, A., Wada, M., Kamiya, K., Hayafune,
M., Kaku, H., and Shibuya, N. (2012). Functional characterization of CEBiP and CERK1 homologs in Arabidopsis and rice reveals the presence of different chitin receptor systems in plants. Plant Cell Physiol 53, 1696-1706.

Shinya, T., Yamaguchi, K., Desaki, Y., Yamada, K., Narisawa, T., Kobayashi, Y., Maeda, K., Suzuki, M., Tanimoto, T., Takeda, J., Nakashima, M., Funama, R., Narusaka, M., Narusaka, Y., Kaku, H., Kawasaki, T., and Shibuya, N. (2014). Selective regulation of the chitin-induced defense response by the Arabidopsis receptor-like cytoplasmic kinase PBL27. Plant J 79, 56-66.

Shiu, S.H., and Bleecker, A.B. (2001). Receptor-like kinases from Arabidopsis form a monophyletic gene family related to animal receptor kinases. Proc Natl Acad Sci USA 98, 10763-10768.

Shin-Han, S., and Bleecker, A.B. (2003). Expansion of the receptor-like kinase/Pelle gene family and receptor-like proteins in Arabidopsis. Plant Physiol 132, 530-543.

Shiu, S.H., Karlowski, W.M., Pan, R., Tzeng, Y.H., Mayer, K.F.X., and Li, W.H. (2004). Comparative analysis of the receptor-like kinase family in Arabidopsis and rice. Plant Cell 16, 1220-1234.

Silipo, A., Erbs, G., Shinya, T., Dow, J.M., Parrilli, M., Lanzetta, R., Shibuya, N., Newman, M.A., and Molinaro, A. (2010). Glyco-conjugates as elicitors or suppressors of plant innate immunity. Glycobiology 20, 406-419.

Singh, P., Kuo, Y.C., Mishra, S., Tsai, C.H., Chien, C.C., Chen, C.W., Desclos-Theveniau, M., Chu, P.W., Schulze, B., Chinchilla, D., Boller, T., and Zimmerli, L. (2012). The lectin receptor kinase-VI.2 is required for priming and positively regulates Arabidopsis pattern-triggered immunity. Plant Cell 24, 1256-1270.

Smit, P., Limpens, E., Geurts, R., Fedorova, E., Dolgikh, E., Gough, C., and Bisseling, T. (2007). Medicago LYK3, an entry receptor in rhizobial nodulation factor signaling. Plant Physiol 145, 183-191.

Smith, J.M., Salamango, D.J., Leslie, M.E., Collins, C.A., and Heese, A. (2014). Sensitivity to Flg22 is modulated by ligand-induced degradation and de novo synthesis of the endogenous flagellin-receptor FLAGELLIN-SENSING2. Plant Physiol 164, 440-454.

Song, D.H., and Lee, J.O. (2012). Sensing of microbial molecular patterns by Toll-like receptors. Immunol Rev 250, 216-229.

Spallek, T., Beck, M., Ben Khaled, S., Salomon, S., Bourdais, G., Schellmann, S., Robatzek, S., and McDowell, J.M. (2013). ESCRT-I mediates FLS2 endosomal sorting and plant immunity. PLoS Genet 9, e1004035.

Sreekanta, S., Bethke, G., Hatsugai, N., Tsuda, K., Thao, A., Wang, L., Katagiri, F., and Glazebrook, J. (2015). The receptor-like cytoplasmic kinase PCRK1 contributes to pattern-triggered immunity againstPseudomonas syringaein Arabidopsis thaliana. New Phytol 207, 78-90.

Sun, Y., Li, L., Macho, A.P., Han, Z., Hu, Z., Zipfel, C., Zhou, J.M., and Chai, J. (2013a). Structural basis for flg22-induced activation of the Arabidopsis FLS2-BAK1 immune complex. Science 342, 624-628.

Sun, Y., Han, Z., Tang, J., Hu, Z., Chai, C., Zhou, B., and Chai, J. (2013b). Structure reveals that BAK1 as a co-receptor recognizes the BRI1-bound brassinolide. Cell Res 23, 1326-1329.

Takeuchi, O., Hoshino, K., Kawai, T., Sanjo, H., Takada, H., Ogawa, T., Takeda, K., and Akira, S. (1999). Differential roles of TLR2 and TLR4 in recognition of gram-negative and gram-positive bacterial cell wall components. Immunity 11, 443-451.

Tan, Y., and Kagan, J.C. (2014). A cross-disciplinary perspective on the innate immune responses to bacterial lipopolysaccharide. Mol Cell 54, 212-223.

Tang, J., Han, Z., Sun, Y., Zhang, H., Gong, X., and Chai, J. (2015). Structural basis for recognition of an endogenous peptide by the plant receptor kinase PEPR1. Cell Res 25, 110-120.

Tintor, N., Ross, A., Kanehara, K., Yamada, K., Fan, L., Kemmerling, B., Nurnberger, T., Tsuda, K., and Saijo, Y. (2013). Layered pattern receptor signaling via ethylene and endogenous elicitor peptides during Arabidopsis immunity to bacterial infection. Proc Natl Acad Sci USA 110, 6211-6216. 
Torres, M.A., Dangl, J.L., and Jones, J.D.G. (2002). Arabidopsis gp91phox homologues AtrbohD and AtrbohF are required for accumulation of reactive oxygen intermediates in the plant defense response. Proc Natl Acad Sci USA 99, 517-522.

Tör, M., Lotze, M.T., and Holton, N. (2009). Receptor-mediated signalling in plants: molecular patterns and programmes. J Exp Bot 60, 3645-3654.

Vaid, N., Pandey, P.K., and Tuteja, N. (2012). Genome-wide analysis of lectin receptor-like kinase family from Arabidopsis and rice. Plant Mol Biol 80, 365-388.

Veronese, P. (2006). The membrane-anchored BOTRYTIS-INDUCED KINASE1 plays distinct roles in Arabidopsis resistance to necrotrophic and biotrophic pathogens. Plant Cell 18, 257-273.

Wan, J., Zhang, X.C., Neece, D., Ramonell, K.M., Clough, S., Kim, S., Stacey, M.G., and Stacey, G. (2008). A LysM receptor-like kinase plays a critical role in chitin signaling and fungal resistance in Arabidopsis. Plant Cell 20, 471-481.

Wang, J., Li, H., Han, Z., Zhang, H., Wang, T., Lin, G., Chang, J., Yang, W., and Chai, J. (2015). Allosteric receptor activation by the plant peptide hormone phytosulfokine. Nature 525, 265-268.

Wei, T., Chern, M., Liu, F., and Ronald, P.C. (2016). Suppression of bacterial infection in rice by treatment with a sulfated peptide. Mol Plant Pathol doi: $10.1111 / \mathrm{mpp} .12368$.

Willmann, R., Lajunen, H.M., Erbs, G., Newman, M.A., Kolb, D., Tsuda, K., Katagiri, F., Fliegmann, J., Bono, J.J., Cullimore, J.V., Jehle, A.K., Gotz, F., Kulik, A., Molinaro, A., Lipka, V., Gust, A.A., and Nurnberger, T. (2011). Arabidopsis lysin-motif proteins LYM1 LYM3 CERK1 mediate bacterial peptidoglycan sensing and immunity to bacterial infection. Proc Natl Acad Sci USA 108, 19824-19829.

Wu, Y., and Zhou, J.M. (2013). Receptor-like kinases in plant innate immunity. J Integr Plant Biol 55, 1271-1286.

Wulff, B.B.H., Chakrabarti, A., and Jones, D.A. (2009). Recognitional specificity and evolution in the tomato-Cladosporium fulvum pathosystem. Mol Plant Microbe Interact 22, 1191-1202.

Yamada, K., Yamashita-Yamada, M., Hirase, T., Fujiwara, T., Tsuda, K., Hiruma, K., and Saijo, Y. (2016). Danger peptide receptor signaling in plants ensures basal immunity upon pathogen-induced depletion of BAK1. EMBO J 35, 46-61.

Yamaguchi, K., Yamada, K., Ishikawa, K., Yoshimura, S., Hayashi, N., Uchihashi, K., Ishihama, N., Kishi-Kaboshi, M., Takahashi, A., Tsuge, S., Ochiai, H., Tada, Y., Shimamoto, K., Yoshioka, H., and Kawasaki, T. (2013). A receptor-like cytoplasmic kinase targeted by a plant pathogen effector is directly phosphorylated by the chitin receptor and mediates rice immunity. Cell Host Microbe 13, 347-357.

Yamaguchi, Y., Huffaker, A., Bryan, A.C., Tax, F.E., and Ryan, C.A. (2010). PEPR2 is a second receptor for the Pep1 and Pep2 peptides and contributes to defense responses in Arabidopsis. Plant Cell 22, 508-522.

Yan, L., Ma, Y., Liu, D., Wei, X., Sun, Y., Chen, X., Zhao, H., Zhou, J., Wang, Z., Shui, W., and Lou, Z. (2012). Structural basis for the impact of phosphorylation on the activation of plant receptor-like kinase BAK1. Cell Res 22, 1304-1308.

Yoon, S., Kurnasov, O., Natarajan, V., Hong, M., Gudkov, A.V., Osterman, A.L., and Wilson, I.A. (2012). Structural basis of TLR5-flagellin recognition and signaling. Science 335, 859-864.

Zhang, J., Li, W., Xiang, T., Liu, Z., Laluk, K., Ding, X., Zou, Y., Gao, M., Zhang, X., Chen, S., Mengiste, T., Zhang, Y., and Zhou, J.M. (2010). Receptor-like cytoplasmic kinases integrate signaling from multiple plant immune receptors and are targeted by a Pseudomonas syringae effector. Cell Host Microbe 7, 290-301.

Zhang, L., Kars, I., Essenstam, B., Liebrand, T.W.H., Wagemakers, L., Elberse, J., Tagkalaki, P., Tjoitang, D., van den Ackerveken, G., and van Kan, J.A.L. (2014). Fungal endopolygalacturonases are recognized as microbe-associated molecular patterns by the Arabidopsis receptor-like protein RESPONSIVENESS TO BOTRYTIS POLYGALACTURONASES1. Plant Physiology 164, 352-364.

Zhang, W., Fraiture, M., Kolb, D., Loffelhardt, B., Desaki, Y., Boutrot, F.F.G., Tor, M., Zipfel, C., Gust, A.A., and Brunner, F. (2013). Arabidopsis RECEPTOR-LIKE PROTEIN30 and receptor-like kinase SUPPRESSOR OF BIR1-1/EVERSHED mediate innate immunity to necrotrophic fungi. Plant Cell 25, 4227-4241.

Zhang, Y., Zhu, H., Zhang, Q., Li, M., Yan, M., Wang, R., Wang, L., Welti, R., Zhang, W., and Wang, X. (2009). Phospholipase D 1 and phosphatidic acid regulate NADPH oxidase activity and production of reactive oxygen species in ABA-mediated stomatal closure in Arabidopsis. Plant Cell 21, 2357-2377.

Zhang, Z., and Thomma, B.P.H.J. (2013). Structure-function aspects of extracellular leucine-rich repeat-containing cell surface receptors in plants. J Integr Plant Biol 55, 1212-1223.

Zhukov, V., Radutoiu, S., Madsen, L.H., Rychagova, T., Ovchinnikova, E., Borisov, A., Tikhonovich, I., and Stougaard, J. (2008). The PeaSym 37 receptor kinase gene controls infection-thread initiation and nodule development. Mol Plant Microbe Interact 21, 1600-1608.

Zipfel, C., Kunze, G., Chinchilla, D., Caniard, A., Jones, J.D.G., Boller, T., and Felix, G. (2006). Perception of the bacterial PAMP EF-Tu by the receptor EFR restricts agrobacterium-mediated transformation. Cell 125, 749-760.

Open Access This article is distributed under the terms of the Creative Commons Attribution License, which permits any use, distribution, and reproduction in any medium, provided the original author(s) and source are credited. 